\title{
Da imagem à comunicação: situações éticas desafiadoras no ambiente organizacional
}

\author{
From Image to communication: challenging ethical \\ situations in the organizational environment
}

\begin{abstract}
Mônica Cristine Fort I monica.fort@pucpr.br
Graduada em Comunicação (Jornalismo) pela Universidade Federal do Paraná (1988), e em Administração pela Faculdade Católica de Administração e Economia (1989). Mestre em Educação pela Pontifícia Universidade Católica do Paraná (1999) e Doutora em Engenharia de Produção pela Universidade Federal de Santa Catarina (2004). Foi coordenadora do curso de Comunicação Social, Jornalismo, da Pontifícia Universidade Católica do Paraná entre jan/2001

e jun/2012. Tem experiência na área de Comunicação, com ênfase em videodifusão, atuando principalmente nos seguintes temas: jornalismo, televisão, educação, comunicação empresarial e comunicação audiovisual. É autora do livro "Televisão Educativa: a responsabilidade pública e as preferências do espectador".
\end{abstract}

\begin{abstract}
Resumo
Na sociedade definida por Bauman como líquida, manter o foco no trabalho em equipe para o sucesso das organizaçóes parece ser tarefa cada vez mais fluida. Discutir esse quadro é a proposta deste artigo, que apresenta exemplos de situaçóes éticas desafiadoras no ambiente corporativo, como o medo, a rotina, a flexibilidade, o fracasso, os riscos, o coletivo. Para tanto, o texto aborda a imagem organizacional e os valores associados a ela e que podem ajudar a construir um significado positivo ou negativo. Considera-se também a opiniáo de profissionais com experiência em gestão
\end{abstract}

Palavras-Chave: Imagem, organizaçôes, comunicação, desafios.

\begin{abstract}
In the society that Bauman defined as liquid, keeping the focus on teamwork for the success of organizations seems to be an increasingly fluid job. To discuss this context is the proposal of this work that, by examples, presents challenging ethic situations of the corporate environment, such as fear, routine, flexibility, failure, risks, and the collective. Therefore this text addresses the organizational image and its associated values that shall help building a positive or negative meaning, also considering the opinion of professionals with management experience.
\end{abstract}

Keywords: Image, organizations, communication, challenges. 


\section{Considerações iniciais}

Imagem. O conhecimento passa cada vez mais pelas imagens. Parecemos viver uma revolução epistemológica na qual há uma transição do conhecimento alfabético-silábico pelo audiovisual. Miguel Roja Mix comenta, no livro El imaginário - civilización y cultura Del siglo XXI (2006), que crenças, valores e representaçóes, por exemplo, dão ao homem uma identidade social. Ao se gerar confiança, imagina-se que opiniáo é formada. Ao projetar uma imagem, precisamos lembrar que o receptor dessa informação poderá interpretá-la de maneira diferente da que o texto quis transmitir. Uma campanha promocional, por exemplo, de ovos de Páscoa destinados a meninos e a meninas (sendo com embalagens azuis para meninos e rosa para meninas), gerou desconforto. Foi considerada uma campanha sexista, contrária aos padróes democráticos que são discutidos na sociedade:

Baseada em pesquisas com mães e crianças, a Ferrero - fabricante do Kinder Ovo
- apostou em lançamentos "para meninos" e "para meninas" nesta Páscoa. A versão
masculina é azul e traz brinquedos como carros ou avióes. A feminina é rosa e os
brindes são itens como bonecas ou pulseiras. A empresa não previu a possibilidade de
ser taxada de sexista nas redes sociais, mas foi exatamente o que aconteceu. Rendeu até
um abaixo-assinado no site Avaaz.org. (FOGEL, 2013).

Nesse sentido, consideram-se as reflexôes do jornalista Mário Rosa, no livro $A$ sindrome de Aquiles (2001): não há temor maior para empresários, políticos e profissionais de sucesso do que ter suas reputaçóes fortemente abaladas, ou até mesmo destruídas, em decorrência de uma situação crítica que provoque a reação direta da opinião pública. $\mathrm{O}$ mesmo autor, no livro A reputação na velocidade do pensamento - imagem e ética na Era Digital (2006), afirma que organizaçôes (e pessoas ligadas diretamente ou não a tais organizaçôes) precisam investir em uma reputação confiável. "Credibilidade não é uma medalha; é uma poupança!” (ROSA, 2006, p. 142). Portanto, não basta ter uma imagem conhecida. É preciso ser admirada:

...credibilidade, reputação, deve ser encarada como um ativo, como uma poupança. Algo que se deve acumular ao máximo ao longo do tempo, inclusive, para ter de onde sacar, em caso de necessidade [...] Se a credibilidade na esfera pública deve estar afinada com a percep̧̧ão da audiência, nosso desafio agora é tentar entender esse olhar em transformação; é buscar decifrar essa nova forma de ver situada entre o primitivo e o ponto.com. (ROSA, 2006, p. 142).

O presente artigo tem como objetivo analisar situaçóes que, de certa forma, afetam as organizaçóes e seus colaboradores. A partir da noção de liquidez proposta por Bauman, discute-se o medo, a rotina, a flexibilidade, o fracasso, os riscos, o coletivo. Conta-se também com comentários de profissionais de diversos setores econômicos, mas que atuaram ou atuam em cargos de gestáo e que, convidados a responder a um questionário, se comprometeram sem que fossem identificados. Observamos que foram convidados 100 profissionais, mas apenas 12 atenderam ao convite e encaminharam respostas que puderam ser consideradas significativas no contexto do artigo. 


\section{Vigilância, imagem e segredo}

Atualmente, somos vigiados constantemente. Os aparelhos de telefone celular mais recentes - que têm múltiplas funçôes - são capazes de produçôes audiovisuais com qualidade razoável, dando projeção a fatos que sem a tecnologia provavelmente não seriam conhecidos do grande público. Hoje, se chamamos algo de segredo é porque tal segredo ainda não aconteceu, pois o que já ocorreu provavelmente já foi exposto ao mundo.

A lista de exemplos é extensa, mas citaremos o caso da ex-ministra da Juventude e Cultura da Costa Rica, Karina Bolaños, que teve um vídeo sensual vazado na web. O caso ocorreu em julho de 2012, mas, segundo declaraçóes de Bolanós feitas à imprensa na ocasião, o vídeo tinha sido feito por ela mesma em 2007 e teria sido roubado de seu computador - o responsável pelo roubo, ainda segundo a ex-ministra, inclusive a chantageava há algum tempo. Como as imagens repercutiram negativamente na internet, a então ministra foi demitida:

O escândalo ganhou proporção ainda maior após a presidente da Costa Rica, Laura Chinchilla, ter optado pela demissão sumária de Bolaños. Ainda que as informaçóes que circularam estejam estritamente relacionadas com a vida privada de Bolaños e não com o seu trabalho como funcionária pública, o afastamento do cargo se deu para que ele possa enfrentar esse caso no âmbito privado', afirmou o ministro da Cultura, Manuel Obregón. (BBC Brasil, in G1, 2012)

A projeção de um colaborador, dependendo de como acontece, pode comprometer toda a imagem institucional da organização. É comum escutarmos comentários relacionados aos políticos: "Nenhum presta", "são todos iguais", "só estão lá para defenderem interesses próprios"... Açôes individuais podem ser, devido ao imaginário construído a partir da recepçáo de mensagens midiáticas, consideradas coletivas, como se todos os indivíduos daquele segmento tivessem exatamente o mesmo comportamento.

O título de uma obra de 1917 do italiano Luigi Pirandello: Assim é, se the parece - tradução de Così è (se vi pare) - ilustra bem as situaçóes apresentadas por veículos de comunicaçáo. Sendo reportadas por jornalistas, acredita-se despertar credibilidade. Dois casos de repercussão na mídia em 2010 (um local e um mundial) chamaram a atenção.

O primeiro caso, de repercussão local, foi o de um hospital particular de Curitiba, que recusou atendimento a uma pessoa em crise de saúde que não tinha recursos para pagar a conta. Em agosto de 2010, um cobrador de ônibus na capital paranaense começou a sofrer o que parecia ser uma crise de hipertensão. Era final de tarde e o trânsito estava muito congestionado. Os passageiros do ônibus, solidários, observaram que o veículo estava passando em frente a um hospital da cidade. Pediram para o motorista parar e levaram o cobrador para ser atendido. Mas funcionários do hospital negaram atendimento de emergência porque era uma instituição privada e indicaram aos passageiros que chamassem o Serviço de Atendimento Móvel de Emergência (Samu), que é público. 
A situação ficou constrangedora, pois com as dificuldades do trânsito, o socorro demorou a chegar e o paciente passou a ser atendido na calçada, em frente ao hospital, pelos próprios passageiros, que náo tinham conhecimentos médicos, mas seguiam as instruçôes, por telefone, do socorrista da ambulância pública. Um detalhe é que o celular serviu para passar informaçôes sobre como atender ao enfermo, mas outro aparelho de telefone móvel foi utilizado para gravar imagens daquela cena dramática: chão da calçada, noite fria, falta de equipamentos ou higiene, pessoas indignadas. Ao fundo, o hospital - sua logomarca associada ao desrespeito a um trabalhador que naquele momento precisava de atendimento médico.

A frase Assim é, se lhe parece resume o que pode ter resultado para o hospital a recusa no atendimento. Passageiros indignados fizeram questão de registrar o ocorrido, inspirados no potencial jornalístico do caso. As cenas do episódio com o cobrador foram parar na televisão e a Internet deve perpetuar o audiovisual ${ }^{1}$. Cabe ressaltar que o hospital se defendeu informando que, por ser uma instituiçáo privada, não poderia atender ao paciente, que preferiu solicitar pronto socorro público. Mas o assunto tornou-se manchete, reportagem principal do telejornal regional de maior audiência na cidade. A imagem do hospital foi divulgada por ter negado socorro a um cidadão. Assim é, se lhe parece! Não há justificativa suficiente para convencer o espectador que aquela instituição é confiável, séria, ética, responsável. Afinal, se o que traduz uma imagem são os valores associados a ela (ROSA, 2006); não atender o cidadão porque ele não podia pagar pelo atendimento deixa de lado um dos principais valores humanos, o direito à vida.

O outro exemplo, que também teve repercussão política e midiática - e em proporçốes infinitamente maiores - aconteceu no Chile. Foi a explosão na Mina San José, em Copiapó. A mineradora, a cidade, o deserto de Atacama, o país foram expostos mundialmente. E o resgate dos $33 \mathrm{mi}$ neiros, que estavam presos há mais de 600 metros de profundidade, 69 dias depois, foi apresentado ao vivo para o mundo inteiro. $\mathrm{O}$ assunto, trágico, merecia as páginas dos jornais, as manchetes de rádio, televisão e Internet. Questionou-se, inclusive, a semelhança do episódio com o filme de Billy Wilder, A Montanha dos Sete Abutres.

Acompanhar a dor e a esperança das famílias, a situação em que se encontravam os mineiros, o fim do confinamento forçado desperta o interesse do público. O repórter da brasileira Rede Globo de Televisão, Carlos de Lannoy, informou em uma reportagem que mais de 1500 jornalistas estiveram no deserto de Atacama para acompanhar o desfecho da história (LANNOY, 2010). Entre as cenas comoventes reportadas pelos profissionais de comunicação que transmitiram o evento, uma delas chega a ser engraçada; um dos mineiros, Yonni Barrios, foi "recebido pela amante", segundo jornais brasileiros. Uma questâo de família, um relacionamento privado, foi apresentada - para o mundo inteiro - diante das câmeras de televisão: 
A volta à superfície de Yonni Barrios pôs fim, esta quarta-feira, a um dos maiores suspenses relacionados com o resgate dos 33 mineiros presos em uma jazida no norte do Chile, depois que sua esposa e amante disputaram quem o receberia. Há várias semanas no exterior da mina San José, Valenzuela e Marta Salinas - esposa legitima de Barrios há 28 anos - chegaram a se agredir fisicamente ao disputar quem seria sua companheira. Finalmente, foi a amante quem o recebeu com um longo abraço na saída do duto. (FRANCE PRESSE, 2010)

Mas o que nós, espectadores, leitores, ouvintes, internautas, temos a ver com isso? E o que representam esses exemplos para as empresas? As organizaçôes devem entender que a sociedade do conhecimento é interligada, interativa e intencionada (bem ou mal, mas intencionada). Isso significa que um pequeno fato, que poderia representar um problema administrativo ou pessoal, por exemplo, pode virar um caso comprometedor. Um erro local náo representa mais um dano local, como no passado, mas provoca um dano global. As empresas não podem pensar dentro de quatro paredes, pois elas estão nos quatro cantos do mundo. Portanto, se desprezarem a comunicação, considerando um gasto e não um investimento, podem colocar em risco sua tradição.

Para a confecção deste texto, convidamos por meio de mensagem eletrônica 100 profissionais das áreas de Comunicação, Direito, Administração e Educação, que ocupam ou ocuparam cargos de gestão, para responderem um questionário elaborado por meio da ferramenta gratuita de pesquisa Survey Monkey. Foi selecionado o dia 23 de março, das $14 \mathrm{~h}$ às $22 \mathrm{~h}$, para considerar respostas significativas à construção do artigo. No período de tempo mencionado, 12 pessoas responderam à pesquisa.

Vejamos o que elas entendem como imagem institucional. "É a percepção que os públicos têm sobre as açôes de determinada empresa pública ou privada", respondeu um dos participantes. "A forma como uma empresa se apresenta no mercado", comentou outro respondente. Alguém, provavelmente da área da Comunicação, apresentou uma definição mais técnica: "Na área da comunicação corporativa, representa a preocupação com a imagem da organização no âmbito institucional. A imagem institucional esta ligada a aspectos internos como comunicação interna e clima organizacional e no aspecto externo ao relacionamento da empresa e marca com o consumidor e com os stakeholders".

Há também quem não associe a imagem do colaborador com a própria imagem da instituição, como se fosse algo imposto pela própria organização: "É quando as pessoas que levam a imagem institucional são felizes, realizadas com o que fazem... e não aquilo que a empresa enxerga ou tenta passar como imagem... ideal de instituição", mencionou outro participante. Entre as respostas ainda encontramos: "Na verdade é algo individual, trata-se do que as pessoas pensam sobre a instituição. A instituição pode fazer algo positivo ou negativo com relação a sua imagem dependendo de sua comunicação e principalmente de suas atitudes". Mas quais devem ser as atitudes da organização para que ela tenha boa imagem institucional? 
Para Mário Rosa (2006), a verdade é o que vemos como verdade. E no esforço de poupar credibilidade, as imagens precisam estar associadas a valores positivos. Trata-se de uma atividade permanente. A escolha do autor, que escreve uma obra repleta de exemplos, se deve pela reflexão que fazemos das relações de trabalho na modernidade líquida (BAUMAN, 2001). São açóes que passam pelas imagens, que estáo tanto na realidade concreta quanto na dimensão da informação em tempo real. Bauman, entre os temas pelos quais se refere à liquidez, analisa também o Medo Líquido (2008). Se há uma situação presente na realidade concreta das sociedades líquidas é o medo: de perder o emprego, da violência urbana, do terrorismo, da falta de amor, da solidão... e o medo é provocado pela dimensão da informação em tempo real. Um hospital pode ser apresentado como a instituição que condena carentes à morte, ou em um acidente trágico, um dos sobreviventes é visto como o Don Juan pelo qual mulheres disputam quem vai garantir seus 15 minutos de fama (mundial).

\section{Situações éticas desafiadoras no ambiente organizacional}

Estamos à deriva. $\mathrm{O}$ medo (líquido) provoca mal estar nas relaçóes de trabalho. As pessoas parecem temer serem passadas para trás, perderem oportunidades, ficarem sem projeção. Como se ladróes, de repente, invadissem seu ambiente profissional e as fizessem reféns (das circunstâncias). Os inseguros, quando não executam tarefas que diante da percepção pública sejam essenciais, podem ficar tentados a derrubar o oponente (colega?). Fala-se tanto da necessidade do trabalho em equipe e, ainda assim, parecemos observar cada vez mais as pessoas "ensimesmadas", ou seja, individualistas, com a falsa desculpa de que quem não interage é o outro: "Eu estou disponível, os outros não querem trabalhar comigo". Não há laços fortes, não há longo prazo.

Perguntamos aos respondentes o que eles achavam da segurança em seu ambiente de trabalho. Não se associou segurança à estabilidade profissional ou à violência urbana. A intenção era descobrir a associação que o gestor faz quando o assunto é segurança. Assim, as respostas foram bastante diferentes entre si. Desde quem comentou que no momento não está trabalhando e por isso não poderia responder sobre a segurança no ambiente profissional a "é a proteção individual, no meu caso, luva mascara, bota, óculos, avental, e por aí vai."; "Fraca. Segurança da Informação deveria ser prioridade em todas as empresas."; "Cada área tem aspectos bem particulares na questão de segurança. Tem ambientes que o nível de segurança cria um ambiente de grande stress."; "Náo considero o ambiente em que trabalho seguro"; "Sinto-me inseguro, pois não há mais confiança organizacional. As empresas estão adotando modelos eficientes no que diz respeito a resultados financeiros, mas péssimos se levar em consideração que as pessoas estão sendo completamente descartadas".

No ambiente organizacional, também observamos a rotina, mencionada por um dos respondentes no quesito segurança: "Empresas cada vez mais bisbilhotam a rotina dos funcionários, gerando intimidação e dificultando o clima organizacional". É o que leva as pessoas ao desânimo, à falta de desafios. E como sabemos que o outro nos observa, parecemos 
manter voluntária, mas compulsoriamente, essa rotina. Os participantes da pesquisa também puderam comentar especificamente a esse respeito, e têm a dizer: "(A rotina lhe) deixa distraído, você não presta mais atenção em nada a sua volta."; "Em certos momentos, a rotina me dá segurança, mas em outros me entedia."; "Rouba os sonhos. Robotiza tarefas que deveriam ser prazerosas."; "cansa”; "inquieta”; "incomoda”. Uma única voz dissonante no grupo de respondentes: "Traz organização e equilíbrio".

A justificativa a essa, digamos, "mesmice”, passa também pela complexidade das sociedades hipermodernas (LIPOVETSKY, 2004), com a tecnologia que nos expóe ao mundo. Sorria, você está sendo filmado. Essa frase, que encontramos em elevadores, corredores, recepçóes de instituiçôes públicas e privadas, nos dá uma noção de como a sociedade da informação nos deixa expostos. Todos parecemos viver em um grande laboratório, sendo vigiados o tempo todo. Ferramentas do Google, por exemplo, permitem localizar pessoas e endereços em quase todos os pontos do planeta. Alguns serviços, como o Google Earth (STREET VIEW, 2011), têm flagrado pessoas em situaçóes constrangedoras: tomando sol nuas em suas próprias casas, trocando de roupa atrás de automóveis na doce ilusão de que ninguém pode ver, fazendo sexo...

E o Google Street View flagrou mais um caso curioso. Desta vez, foi na cidade de Manchester, na Inglaterra. O serviço de localização do Google registrou um casal em um beco deserto fazendo coisas indiscretas. As imagens mostram uma mulher, segundo o site Gawker, prostituta, masturbando um homem. O flagra foi divulgado pelo site Google Sightseeing, especialista neste tipo de incidente, e passou a circular em outras páginas e nas redes sociais nesta última quinta-feira (14). Pouco depois de tomar conhecimento do caso, o Google rapidamente retirou as imagens do ar. No entanto, obviamente, o "estrago" já estava feito. (JESUS, 2013). ${ }^{8}$

Somos vigiados constantemente. E qualquer aparelho de telefonia móvel é capaz de captar e transmitir imagens, sons... todos somos pessoas públicas, "e deixamos rastros" (ROSA, 2006). É uma dependência tecnológica. Em um caso de assalto no qual fomos vítimas, decidimos colocar no dia seguinte uma frase em nossa página do Facebook: "Como são traumáticos os assaltos à mão armada. Reféns em nossa própria casa”. Pessoas de diversos lugares do mundo queriam saber o que tinha acontecido - e essa não era nossa intenção. Não quisemos provocar a comoção. Foi um desabafo de quem não costuma colocar informaçôes pessoais no mural do Facebook, por prezar demais a privacidade, a particularidade.

Os exemplos citados ao longo do texto teriam como ser mantidos em segredo? Dificilmente. A tecnologia proporciona uma instantaneidade capaz de propagar uma informação a milhões de pessoas em tempo real, e que não se restringe apenas à área geográfica em que as açóes se dão. Mesmo assim, os respondentes da pesquisa acreditam que os segredos podem ser mantidos. Das 12 respostas, apenas quatro citam que a tecnologia desvenda os segredos: "hoje em dia qualquer hacker consegue ter acesso ao que deseja com um pouco 
de empenho.”; "ela estimula a exibição pública de fatos que deveriam ficar na esfera privada. É um fetiche contemporâneo.”; “estamos sendo vigiados em todos os locais. Recursos como câmeras de segurança e até mesmo localizadores (GPS, Google Earth...) assustam.”; “O advento da Internet tornou tudo muito rápido e próximo. Se uma atriz famosa, por exemplo, é vista saindo de um consultório ginecológico, logo começam as especulaçôes se ela está grávida”.

Os demais respondentes acreditam que ainda há mecanismos para se manter a discrição. Destacamos alguns comentários: "Ainda há livre-arbítrio por parte de seus usuários, de expor ou resguardar determinados assuntos. Acredito que a tecnologia ampliou o alcance e o tempo das informaçôes."; "os segredos continuam existindo, o que fez a tecnologia foi aflorar o lado mais humano das instituiçôes e isso é visto como positivo pela maioria das pessoas."; "qualquer coisa além daquilo que quero mostrar torna-se invasão de privacidade, sujeito a processo indenizatório..."; "se fosse assim não teríamos produtos exclusivos."; "Aquilo que ainda não caiu na rede pode ser segredo".

E é nesse mesmo aspecto que apontamos a flexibilidade como outra situação ética desafiadora. A adaptação às condições tecnológicas pode ser difícil, mas é necessária. Se nos anos 1990 discutia-se tanto a resistência à mudança, hoje parecemos discutir a resistência à permanência. Tudo muda o tempo todo. O que hoje é necessário, amanhã pode ser uma prática que deve ser deixada de lado. Como não sermos flexíveis a essa realidade líquida?

E como "ler" essa realidade virtual? Nas relaçôes de trabalho, os acordos e contratos formais são necessários à proteção dos sujeitos. Cada decisão pode provocar uma reação inadequada. Como justificar a permanência de sujeitos em organizaçóes porque são protegidos por partidos políticos, legislaçôes, sindicatos, organizaçóes que nem sempre defendem o progresso das instituiçóes? Mas também, como sentir-se amparado, protegido, seguro nas próprias organizaçóes onde hoje o sujeito é necessário, leal e fiel, mas amanhã, graças a novos métodos ou modelos gerenciais, ele pode se tornar descartável, sem ao menos entender o que aconteceu, pois em sua mente ficam dúvidas: "Mas não era isso que sempre me pediram? Eu nunca fiz nada errado! Por que, agora, não precisam mais de mim?”.

Aos participantes da pesquisa, foi então questionado como definiriam sucesso. As respostas foram: "conseguir realizar meus projetos, independente da relação com dinheiro.”; “Ter êxito em algo.”; "A pessoa adquirir estabilidade e condiçóes suficientes para poder agir no ambiente (que tanto pode ser o ambiente organizacional como o ambiente onde estão as pessoas com quem se importa) conforme o que deseja. Penso que isso é verdadeiramente realizar-se por meio do trabalho, e trabalhando para modificar uma realidade que a incomoda, essa pessoa poderá realizar-se como ser humano."; "realizar sonhos, conquistar desafios.”; “Algo que vem com o tempo.”; "Meta.”; “Sucesso é fazer o que gosta reservando tempo para uma agenda rica e diversa."; "Cada um 
corre atrás da sua felicidade, não adianta ter sucesso e se sentir sozinho."; "O prazer de fazer o que gosta ao lado de pessoas que fazem parte da sua vida (família e amigos)."; "Felicidade e satisfação naquilo que faço, com um pouquinho de dinheiro...”; "Reconhecimento, respeito.”; "Algo difícil de conseguir na atualidade". Observamos que, para os participantes desta pesquisa, o sucesso não está relacionado à recompensa financeira, mas sim ao prazer de viver bem e de ser respeitado no ambiente em que o sujeito se encontra. As relaçóes de trabalho devem ser claras, objetivas, assertivas. Respeito gera segurança.

\section{Considerações finais}

Assumir riscos na modernidade líquida é natural. Para tanto, é importante sempre refletir sobre as açóes adotadas. O processo de tomada de decisão inclui muitas variáveis. Ao saber que o sujeito da Era da Informação está sendo constantemente monitorado, exigem-se precauçôes e, sobretudo, transparência. O jornalista Mário Rosa (2006) apresenta o que chamou de "Os dez mandamentos da nova reputação"; são eles: 1) Não desprezarás a tecnologia - deve estar no topo de qualquer planejamento; 2) Romperás com velhos condicionamentos - adquirir novos conhecimentos e desprezar os que já não funcionam mais; 3) Viverás sempre em público - todos somos pessoas públicas (e deixamos rastros); 4) Obedecerás a uma nova Ética - adotar preventivamente uma nova forma de conduta; 5) Não mentirás - mentir é expor-se a um enorme risco de contestação; 6) Serás uma marca - construir um significado claro e positivo perante a percepção alheia; 7) Serás mais transparente - a tecnologia irá decretar a morte de segredos; 8) Não esquecerás o passado - nem todos os condicionamentos antigos devem ficar desativados; 9) Viverás em duas dimensôes - realidade concreta e dimensão da informação em tempo real; 10) Aprenderás a ver e a se expor - uma nova forma de ver implica numa forma nova de ser visto.

Os sujeitos precisam admitir sucessos e fracassos. E é importante observar que eventuais perdas não são fracassos. As associaçóes com o futebol levam a interpretaçôes equivocadas. Em uma partida, alguém tem de ganhar... nem mesmo empates não são vistos como bons resultados. Há um opressor e um oprimido, um mocinho e um bandido. Isso não deveria ocorrer, pois, na liquidez das relaçóes humanas, se o mocinho estiver "bem iluminado", sua imagem positiva não precisará ser, necessariamente, associada ao fracasso. Ele pode resgatar um bocado da conta-poupança da credibilidade, um montante suficiente para manter-se bem diante do olhar público. Mário Rosa (2006) afirma que o que traduz uma imagem são os valores associados a ela. $\mathrm{O}$ autor nos propóe um teste:

Se você fosse instado a responder: quem foi o pai mais carinhoso? Digamos que houvesse apenas as seguintes opçöes:

( ) O brasileiro Sérgio Vieira de Mello

( ) Saddam Hussein

[...] não está sendo perguntado quem possuía os valores éticos mais apropriados ou qual dos dois era pessoalmente o homem mais admirável. Até pela trajetória de ambos, poucos duvidariam que a vida do brasileiro, morto, vitima de um atentado 
cruel, jamais esteve associada aos abusos e barbaridades que pesam na biografia de Saddam. [...] Como o brasileiro tem uma imagem positiva, tendemos a atribuir a ele os atributos positivos. Atribuimos à imagem negativa de Saddam valores igualmente negativos. Quando uma imagem é positiva, atribuimos a ela virtudes que ela não tem e atenuamos defeitos que verdadeiramente possui. Quando negativa, atribuimos defeitos talvez inexistentes e desconsideramos virtudes reais. O que dá significado a uma imagem são os valores associados a ela. (ROSA, 2006, p. 139).

Entre os valores positivos nas relaçóes de trabalho, estáo a atuação integrada, a sinergia, a colaboração. Será um trabalho coletivo ou serão açôes individuais? $\mathrm{O}$ verdadeiro líder conjuga o verbo vencer sempre no plural: "nós vencemos". Mas muitas pessoas parecem adotar o que há muito tempo se comenta negativamente no futebol: "Eu venci, nós empatamos, vocês perderam". A equipe procura o sucesso coletivo. Trabalhar com as pessoas que náo compreendem esse significado é o desafio das organizaçóes líquidas e de seus gestores (líderes?) fluidos.

Os respondentes do questionário que serviu como fonte de informação na elaboração deste texto também apresentaram comentários a respeito do ambiente de trabalho ideal. Como respostas, destacamos: "Ambiente organizado.”; "Aquele onde há respeito, polidez, condiçóes básicas de trabalho, harmonia e transparência das informações.”; “O que tem horário flexível, que não exige adaptações rígidas de comportamento e pensamento à sua filosofia, que dê liberdade a quem trabalha nele para agir conforme o que deseja, na medida do possível, e que não veja o funcionário apenas como o funcionário."; "Aquele em que respeita as diferenças, exalta as qualidades e investe nos colaboradores, em negócios ecossustentáveis e na comunidade."; "O ambiente com clareza nos processos, nas escolhas, no tratamento."; "Flexível, respeitando o tempo de maturação das ideias e o ritmo e habilidades de cada um."; "Livre de protocolos e formalismos... Livre também de situaçôes constrangedoras. Tem que ser aberto, transparente, de preferência sem conceitos 'business' que só servem para pensar que dinheiro e lucro a qualquer custo é melhor que o respeito ao próximo..."; "Um ambiente de parceria, de troca, de trabalho em equipe ninguém é nada sozinho". Este coro náo deve ser ignorado. Um ambiente organizado em que as pessoas se respeitem, independente de seu nível hierárquico, um clima de reconhecimento coletivo, é considerado ideal. Informaçôes claras e precisas contribuem para a geração e a manutenção deste clima.

A comunicação de uma organização (e aqui incluímos também as relações de trabalho) não deve ignorar os fatos, superdimensioná-los, manipulá-los ou mentir em relação a eles. Portanto, há desafios a serem seguidos, como: criar a cultura da comunicação; construir e consolidar o relacionamento com os pares e com a mídia; construir imagem e reputação positiva; definir estratégias, estruturas, operaçôes e investimentos. (VIANA, 2004). É preciso investir em comunicação continuada, porque o exercício para associar a imagem da organização a valores positivos é uma ação permanente. Naturalmente, nesse processo, a transparência e a prestação de contas à sociedade são fatores balizadores das ações da organização. Ética é condição para o exercício de suas atividades. 


\section{Referências Bibliográficas}

BAUMAN, Zigmunt. Modernidade líquida. Rio de Janeiro: Jorge Zahar Editor, 2001. Medo líquido. Rio de Janeiro: Jorge Zahar Editor, 2008.

$\mathrm{BBC}$ Brasil. Video sensual provoca demissão de vice-ministra na Costa Rica. Em imagens que caíram na web, vice titular da pasta de Juventude e Cultura aparece em trajes íntimos. <http://g1.globo. com/mundo/noticia/2012/08/video-sensual-provoca-demissao-de-vice-ministra-na-costa-rica.html> (Acesso em 19 mar 2013).

FRANCE PRESSE. Chile: mineiro Yonni Barrios é recebido pela amante. 13 out 2010. <http://g1.globo.com/mundo/noticia/2010/10/chile-mineiro-yonni-barrios-e-recebidopela-amante.html> (Acesso em 14 out 2010). FOGEL, Adriana. As marcas que já cometeram gafes de marketing. Veja alguns casos de açóes de publicidade que deram o que falar. 19 mar 2013. <http://br.financas.yahoo.com/noticias/marcas-que-j-cometeram-gafes-marketing-123300770--finance.html?page $=5>$ (Acesso em 19 mar 2013).

GAZETA DO POVO. Cobrador de ônibus passa mal em frente a hospital, mas é atendido por passageiros. Rede Paranaense de Comunicação. 05 ago 2010.

<http://www.gazetadopovo.com.br/vidaecidadania/conteudo. phtml?id=1032609> (Acesso em: 13 out 2010).

JESUS, Aline. Casal com 'mão boba' é flagrado pelo Google Street View. Tech Tudo Notícias. Globo.com. <http://www.techtudo. com.br/noticias/noticia/2013/03/casal-com-mao-boba-e-flagrado-pelo-google-street-view.html> (Acesso em : 13 mar 2013).

LANNOY, Carlos de. Clima no acampamento Esperanza, no Chile, é de alivio e solidariedade. GLOBO.COM. <http://g1.globo.com/ bom-diabrasil/noticia/2010/10/clima-no-acampamento-esperanca-no-chile-e-de-alivio-esolidariedade.html> (Acesso em: 13 out 2010)

LUCAS, Luciane (org.) Media Training - como agregar valor ao negócio melhorando a relação com a imprensa. Sáo Paulo: Summus, 2007.

MIX, Miguel Rojas. El imaginario: civilizacion y cultura del siglo XXI. Buenos Aires (Argentina): Prometeo Libros, 2006.

ROSA, Mário. A sindrome de Aquiles. São Paulo: Editora Gente, 2001. - A reputaçáo na velocidade do pensamento. São Paulo:

Geração Editorial, 2006. 
STREET VIEW: imagens registradas causam polêmicas. Disponível em: <http://ajudadaweb.wordpress.com/2010/11/25/street-view-imagens-registradas-causam-polemicas/>. (Acesso em: 11 jul 2011)

VIANA, Francisco. Comunicação empresarial de A a Z: temas úteis para o cotidiano e o planejamento estratégico. Sáo Paulo: Editora CLA, 2004.

\section{Notas}

1. Uma reportagem com imagens feitas por um cinegrafista amador por meio de celular encontra-se disponível no endereço eletrônico: http://www. gazetadopovo.com.br/vidaecidadania/conteudo.phtml?id=1032609 (acesso disponível em 11 de julho de 2011). 